\title{
Flank wear and I-kaz 3D correlation in ball end milling process of Inconel 718
}

\author{
M.A.S.M. Tahir ${ }^{1 *}$,J.A. Ghani ${ }^{1}$, M.Z. Nuawi ${ }^{1}$, M. Rizal ${ }^{2}$ and C.H.C. Haron ${ }^{1}$ \\ ${ }^{1}$ Department of Mechanical and Materials Engineering, \\ Faculty of Engineering and Built Environment, \\ Universiti Kebangsaan Malaysia, 43600 Bangi, Selangor, Malaysia \\ *Email: mas_amad205@yahoo.com.my \\ Phone: +60197545205 \\ ${ }^{2}$ Department of Mechanical Engineering, Faculty of Engineering, \\ Syiah Kuala University (UNSYIAH), 23111 Darussalam, Banda Aceh, Indonesia
}

\begin{abstract}
Tool wear may deteriorate the machine product quality due to high surface roughness, dimension exceeding tolerance and also to machine tool itself. Tool wear monitoring system is vital to be used in machining process to achieve high quality of the machined product and at the same time improve the productivity. Nowadays, many monitoring system developed using various sensor and statistical technique to analyze the signals being used. In this paper, I-kaz 3D method is used to analyze cutting force signal in milling process of Inconel 718 for monitoring the status of tool wear in milling process. The results from analyzing cutting force show that I-kaz 3D coefficient has a correlation with cutting tool condition. Tool wear will generate high value of I-kaz 3D coefficient than the sharp cutting tool. Furthermore, the three dimension graphical representation of I-kaz 3D for all cutting condition shown that the degree of scattering data increases with tool wear progression.
\end{abstract}

Keywords: I-kaz 3D; Flank Wear; Milling; Inconel 718; Ball End Nose.

\section{INTRODUCTION}

Manufacturing technology nowadays strive for high production rate while maintaining the quality of the product produced in order to fulfilled customers demand. To ensure the quality of the machined product can be achieved, monitoring system of tool wear is vital be implemented so machining operation using worn cutting tool can be avoided. Tool wear monitoring systems are developed by researchers purposely to monitor tool wear since it is one of the machined process output. Tool wear phenomenon is a gradual failure caused by rubbing action between cutting tool and work piece [1-4]. Machining process using worn tool will affect the quality of the machined part, increasing the production time and it could damage the machine itself when the worn tool suddenly breaks. Hence it will increase the manufacturing cost to produce the machined parts $[5,6]$. Cutting force in machining process has relationship with cutting tool condition. Worn cutting tool will require higher cutting force to cut-off the materials compare to sharp cutting tool. Cutting force signal is good indicator for tool wear monitoring. Cutting force can be measured using force sensor such as strain gauge and piezoelectric sensors. Cutting force signals which were generated by the sensor usually can be displayed in time and frequency domains. The signal features can be extracted in time domain including standard deviation, mean, variance, skewness, root means square (rms) and kurtosis. In the 
previous study, many researchers use various techniques to extract the features from the cutting force signal. Abu-Mahfouz [7] used mean, variance, standard deviation, kurtosis and skewness for statistical measures in the time domain. He reported that in most cases, these four statistical parameters tend to reach a constant value for a discrete time history segment of at least 6000 points of data. Briceno et al. [8] used maximum, minimum, mean and standard deviation value of resultant force which represented the important characteristic of a continuous force pattern in selecting an artificial neural network for efficient modeling and accurate simulation of the milling process. Chungchoo and Saini [9] used skewness and kurtosis of force band as input to enhance the accuracy of tool wear prediction in turning operation.

Integrated Kurtosis-based algorithm for Z-filter technique or I-kaz ${ }^{\mathrm{TM}}$ is new method of signal feature extraction that was introduced by Nuawi et al. [10]. The I-kaz ${ }^{\mathrm{TM}}$ method recently has been use to analyze signal from strain gauge sensor to monitor internal combustion engine by Oskoueian and Nuawi [11]. They reported that the variation of I-kaz coefficient value was influenced by the value of amplitude and frequency of each cylinder. Rizal et al.[12] use I-kaz ${ }^{\mathrm{TM}}$ method to extracting features of cutting force and feed force signals from strain gauge sensor. The research finds that the changes of cutting force signal due to flank wear were significantly indicated by increasing of I-kaz coefficient value. The changes of the I-kaz coefficient in feed force have the most effect on predicting flank wear value followed by I-kaz coefficient in cutting force, feed rate, depth of cut, and cutting speed. Karim et al.[13] used I-kaz Multilevel to identify and characterize the change in the signal from piezoelectric sensor for monitoring system in turning process. They reported that a new correlation has been developed between the I-kaz multilevel coefficient of the raw signal and flank wear data. Ghazali et al.[14] used I-kaz ${ }^{\mathrm{TM}}$ method for monitoring facial wear failure of commercial bearing alloys. The result of their study concluded that I-kaz coefficient, $Z^{\infty}$ value were applicable to be used to predict the specific wear rate, $K^{\prime}$ value with the accuracy of 96$99 \%$ and also detailed changes in wear responses were analyzed and displayed in threedimensional spaces. Abdullah et al. [15] used I-kaz ${ }^{\mathrm{TM}}$ method to detect amplitude and frequency by simultaneously obtaining the I-kaz representation and the I-kaz coefficient. The result of this study shows that the fatigue strain data that contains most high amplitude produced highest I-kaz coefficient, $Z^{\infty}$ value. They had concluded that I-kaz ${ }^{\mathrm{TM}}$ method capable for interpreting and monitoring the fatigue damage behavior of an automotive component. Nuawi et al.[16] used I-kaz ${ }^{\mathrm{TM}}$ method to analyze the signals for monitoring the machining process. They proved that the clustering of the machining signal also can be done by I-kaz ${ }^{\mathrm{TM}}$ method. Study done by Aziz et al. [17] used I-kaz 3D to analyze and determine vibration value for Malaysia army 3-tons truck driver and the result shows that, I-kaz 3D can present the whole body vibration (WBV) experienced by the driver. The aims of this study is to apply new statistical analysis method i.e. I-kaz 3D to extract feature from raw cutting force signal of milling Inconel 718 using ball end nose cutting tool in dry cutting condition.

\section{THEORY OF INTEGRATED KURTOSIS BASED ALGORITMA Z NOTCH FILTER (I-KAZTM)}

The I-kaz ${ }^{\mathrm{TM}}$ is acronym for Integrated Kurtosis-based algorithm for Z-filter. This method is pioneered by Nuawi et al. [10]. I-kaz ${ }^{\mathrm{TM}}$ method is developed and formulated based on the scattering or distribution of the data from its centroid concept. The method developed is measuring the degree of data scattering with respect to its centroid. I-kaz ${ }^{\mathrm{TM}}$ method 
mainly composed the time domain dynamic signal into three different frequency range which is low frequency (LF), high frequency [7] and very high frequency (VF). The ranges for each frequency band are:

Low Frequency (LF) ranged from $0-0.25 f_{\max }$

High Frequency [7] ranged from $0.25 f_{\max }-0.5 f_{\max }$

Very High Frequency (VF) range from $0.5 f_{\max }$

In order to measure the scattering of data distribution with respect to its centroid, variance for each frequency band is calculated as Eq.1, Eq.2 and Eq.3

Variance for x-axis (low frequency),

$$
\sigma_{L}^{2}=\frac{\sum_{i=1}^{N}\left(x_{i}^{L}-\mu_{L}\right)^{2}}{N}
$$

Variance for y-axis (high frequency),

$$
\sigma_{H}^{2}=\frac{\sum_{i=1}^{N}\left(x_{i}^{H}-\mu_{H}\right)^{2}}{N}
$$

Variance for z-axis (very high frequency),

$$
\sigma_{V}^{2}=\frac{\sum_{i=1}^{N}\left(x_{i}^{V}-\mu_{V}\right)^{2}}{N}
$$

where $\sigma_{L}^{2}, \sigma_{H}^{2}, \sigma^{2}$ are the variances for each three frequencies band respectively. $x_{i}^{\mathrm{L}}, x_{i}^{\mathrm{H}}$, $x_{i}^{\mathrm{V}}$ are data for the $i$-samples of time in the different range frequency. $\mu_{\mathrm{L}}, \mu_{\mathrm{H}}$ and $\mu_{\mathrm{V}}$ are mean or average for each data of 3 different frequency bands and $N$ is the total number of data point. I-kaz coefficient, $Z^{\circ}$ is square roots of sum of the three different frequency bands squared variance as Eq.4.

$$
Z^{\infty}=\sqrt{\frac{\sum_{i=1}^{N}\left(x_{i}^{L}-\mu_{L}\right)^{4}}{N^{2}}+\frac{\sum_{i=1}^{N}\left(x_{i}^{H}-\mu_{H}\right)^{4}}{N^{2}}+\frac{\sum_{i=1}^{N}\left(x_{i}^{V}-\mu_{V}\right)^{4}}{N^{2}}}
$$

I-kaz coefficient also can be written in terms of variance simplified from Eq. 4 as:

$$
Z^{\infty}=\sqrt{\left(\sigma_{L}^{2}\right)^{2}+\left(\sigma_{H}^{2}\right)^{2}+\left(\sigma_{V}^{2}\right)^{2}}
$$

The signal's $4^{\text {th }}$ statistical moment, kurtosis, $K$ is a global signal statistic which sensitive highly to the spikiness of the data. Kurtosis is very important in feature extraction in order to retain a certain amount of the signal's amplitude range characteristics [18]. Kurtosis for discrete data value can be determined as:

$$
K=\frac{1}{N s^{4}} \sum_{i=1}^{N}\left(x_{i}-\mu\right)^{4}
$$

where $s$ is standard deviation and $N$ is numbers of data. Eq.5 can be written in term of Kurtosis as: 


$$
Z^{\infty}=\frac{1}{N} \sqrt{K_{L} s_{L}^{4}+K_{H} s_{H}^{4}+K_{V} s_{V}^{4}}
$$

To analyze signal from three sensors or three channels of force signal, the derivation of I-kaz ${ }^{\mathrm{TM}}$ method which is I-kaz3D is used. In this method, instead of composing signal into three different frequency ranges to determine I-kaz coefficient, kurtosis, and standard deviation of each signal or channel is used to compute I-kaz3D coefficient. I-kaz 3D coefficient can be calculated using Eq. 8 as shown:

$$
Z_{3}^{\infty}=\frac{1}{N} \sqrt{K_{1} s_{1}^{4}+K_{2} s_{2}^{4}+K_{3} s_{3}^{4}}
$$

Whereas $K_{1}, K_{2}$ and $K_{3}$ are kurtosis for channel 1, channel 2 and channel 3 and $s_{1}$, $s_{2}$ and $s_{3}$ are standard deviation for channel 1, channel 2 and channel 3. Furthermore, I-kaz 3D method can provide a three dimensional graphical representation of the three different channels of cutting force signal at $x$-axis, $y$-axis and $z$-axis

\section{EXPERIMENTAL SET UP}

In this study, the down milling process is performed using CNC DMC $635 \mathrm{~V}$ Eco machine. The machining experiment of Inconel 718 as work material was carried out in dry cutting condition. Work material of Inconel 718 is widely used for aerospace component such as gas turbine blade which requires high temperature strength. Inconel 718 is one of nickel based super alloys family and it is considered as difficult to machine material due to its capable to maintain its strength at elevated temperature, low thermal conductivity and tend to experience work hardening during cutting process. $\left(\sim 600^{\circ} \mathrm{C}\right)$ [19]. Cutting tool used in this study was a Sumitomo ball end nose type milling cutter with nominal diameter of $16 \mathrm{~mm}$. It is a tungsten carbide with $3.97 \mu \mathrm{m}$ thicknesses multilayer physical vapor deposition (PVD) TiAlN/AlCrN grade ACK 300 with precise clamping, BIG Hi-Power Milling chuck DV 40-HMC20-85. The cutting tool has geometry of $10 \mathrm{~mm}$ diameter, $11^{\circ}$ relief angle, $0^{\circ}$ radial rake angle, $-3^{\circ}$ axial rake angle, $90^{\circ}$ approach angle.

The cutting parameters used are shown in Table 1. The machining processes are carried out until the flank wear reached $0.5 \mathrm{~mm}$. According to ISO 8688-2-1989, tool life failure for end milling is $0.3 \mathrm{~mm}$ for uniform flank wear and 0.5 irregular flank wear and catastrophic failure.

Table 1. Cutting parameter.

\begin{tabular}{ccccc}
\hline Run & $\begin{array}{c}\text { Cutting speed, } V_{c} \\
(\mathrm{~m} / \mathrm{min})\end{array}$ & $\begin{array}{c}\text { Feed rate, } f_{z} \\
(\mathrm{~mm} / \text { tooth })\end{array}$ & $\begin{array}{c}\text { Axial depth of cut, } \\
a_{p}(\mathrm{~mm})\end{array}$ & $\begin{array}{c}\text { Radial depth of cut, } \\
a_{e}(\mathrm{~mm})\end{array}$ \\
\hline 1 & 140 & 0.15 & 0.3 & 0.2 \\
2 & 160 & 0.15 & 0.3 & 0.2 \\
3 & 140 & 0.20 & 0.3 & 0.2 \\
4 & 160 & 0.20 & 0.3 & 0.2 \\
\hline
\end{tabular}

Cutting force in this study was measured by using strain gauge-based dynamometer. The cutting force signals are measured in three axes of $x$-axis (main cutting force), $y$-axis (feed force) and $z$-axis (thrust force). Flank wear of the cutting tools are measured by Baty Venture 2510 AB3-V-CNC microscope. Flank wear measurements are performed randomly until it is exceeding the flank wear limit. Figure 1 shows the complete illustration of experimental set up in this study. 
Milling process
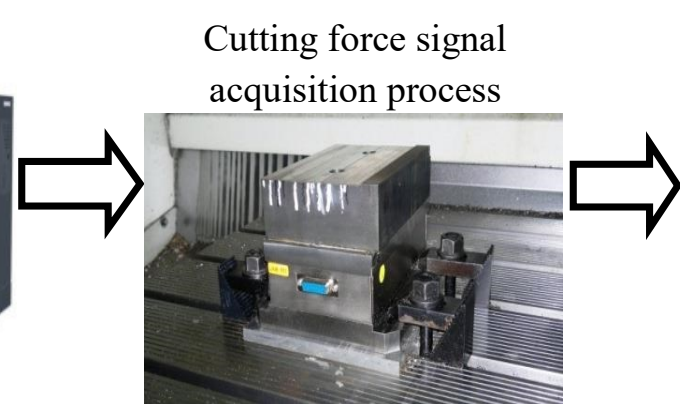

Signal conditioning

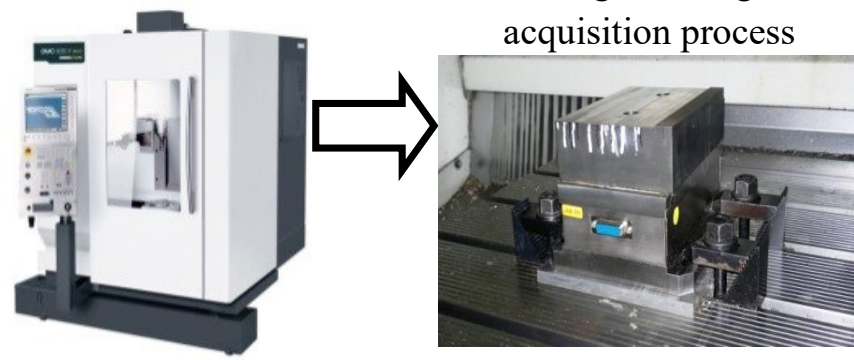

using NI 9237

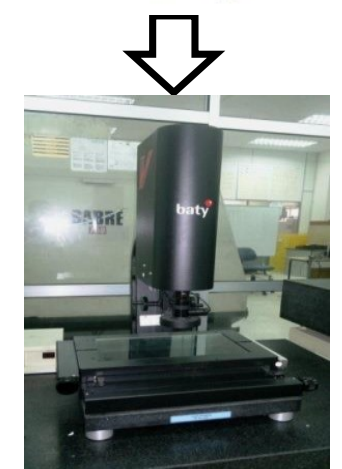

Flank wear $(V B)$ measurement using Baty Microscope

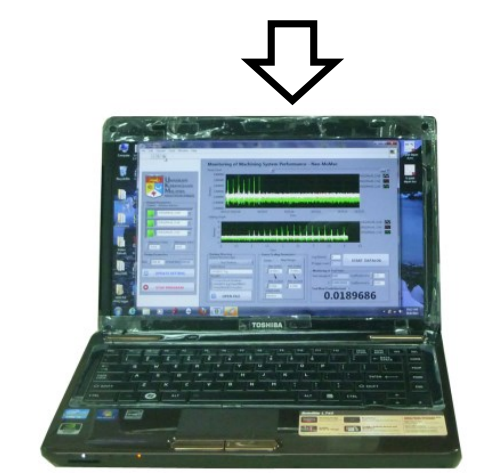

Display and saving data into PC

Figure 1. Experimental set-up.
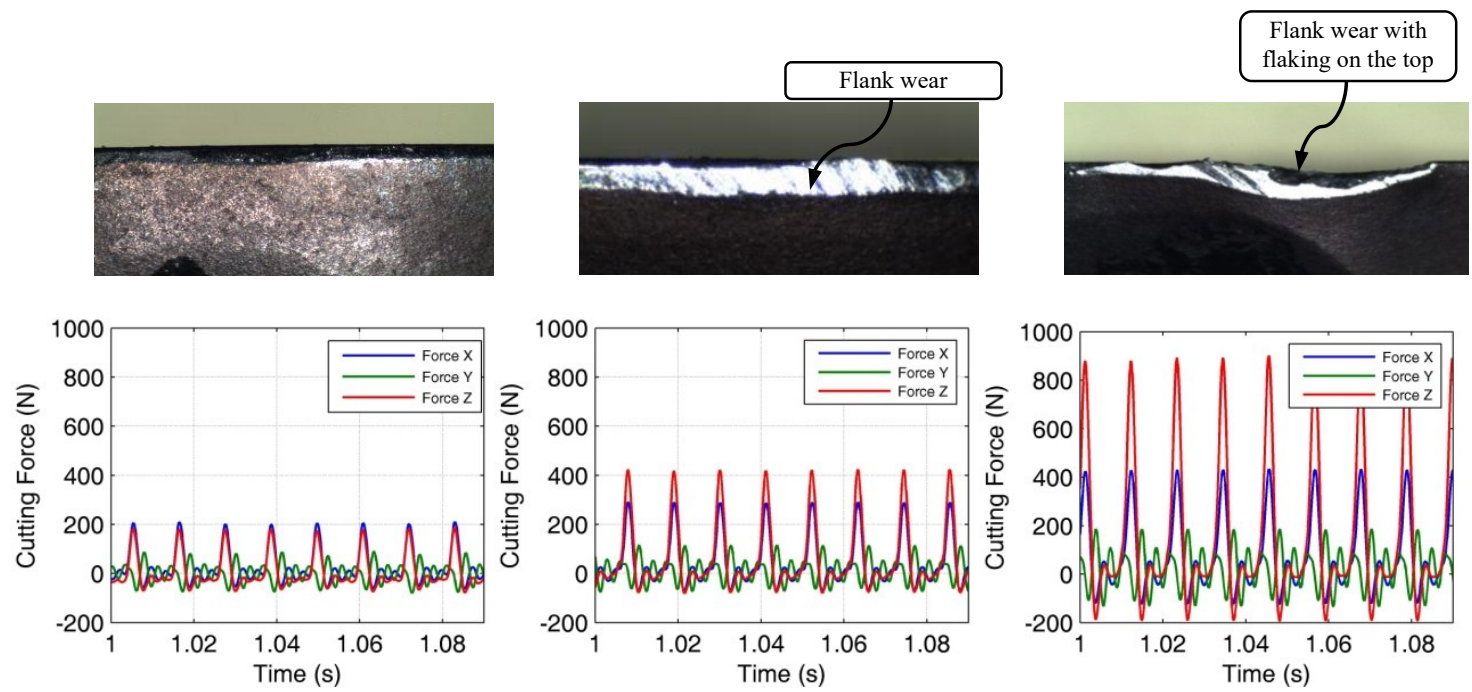

Figure 2. The cutting forces during milling process: (a) at flank wear $=0.144 \mathrm{~mm}$, (b) at flank wear $=0.242 \mathrm{~mm}$, and (c) at end of cutting, flank wear $=0.519 \mathrm{~mm}$.

\section{RESULTS AND DISCUSSION}

After flank wear of cutting tool reach $0.5 \mathrm{~mm}$ for all cutting condition, all cutting signal produce by strain gauge based dynamometer is analyzed using I-kaz 3D method. Figure 2 shows the three phase of cutting signal with its cutting tool condition for $1^{\text {st }}$ cutting condition $\left(V_{c}=140 \mathrm{~m} / \mathrm{min}, f_{z}=0.15 \mathrm{~mm} /\right.$ tooth, $a_{p}=0.3 \mathrm{~mm}$ and $\left.a_{e}=0.2 \mathrm{~mm}\right)$. 


\section{Experimental set 1}
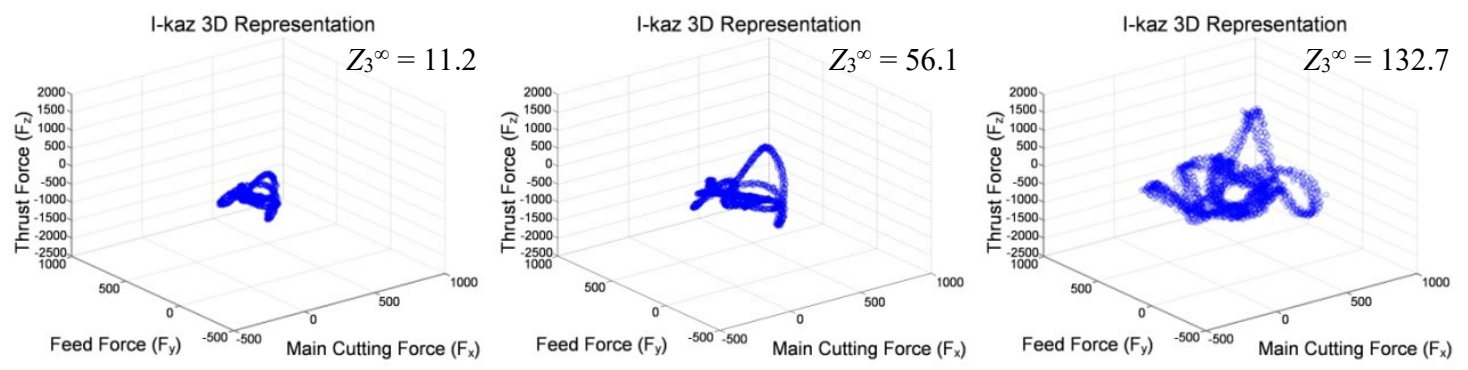

Experimental set 2
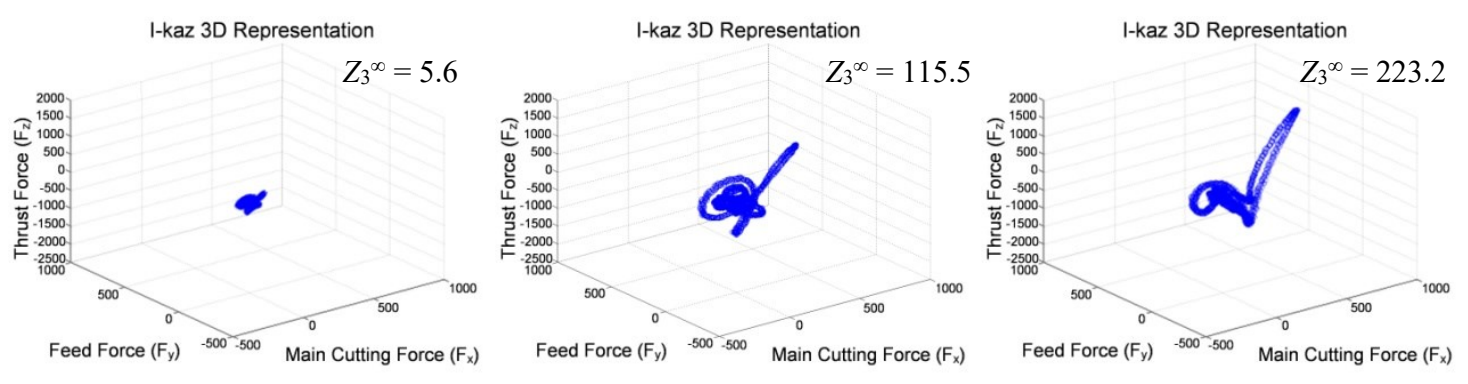

\section{Experimental set 3}
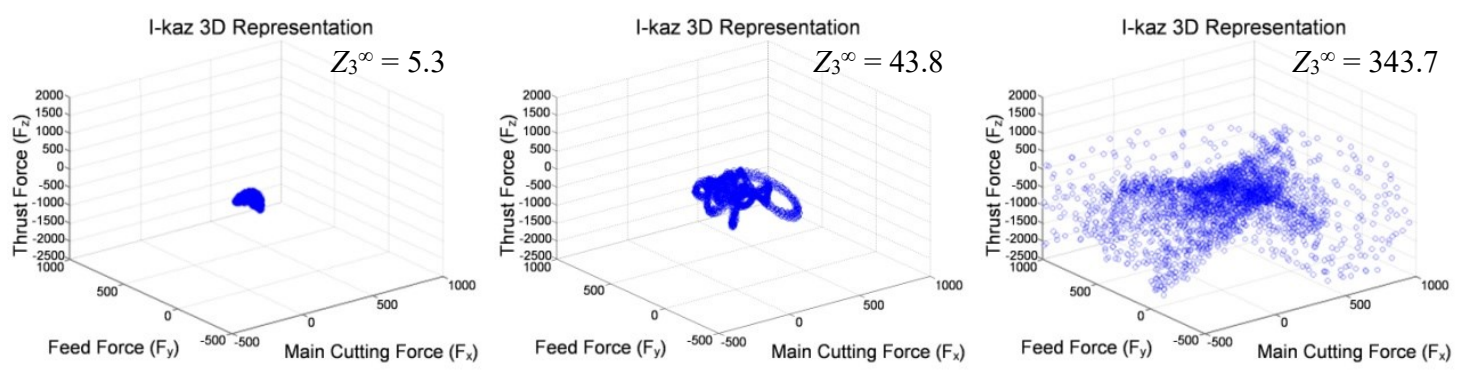

Experimental set 4

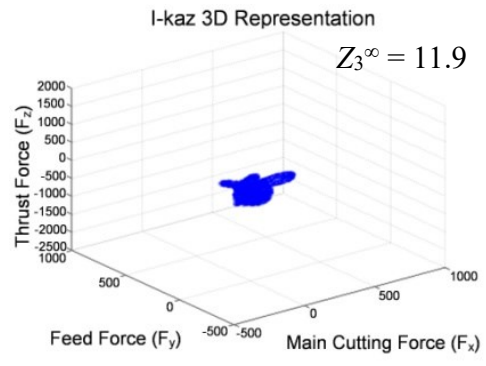

(a)

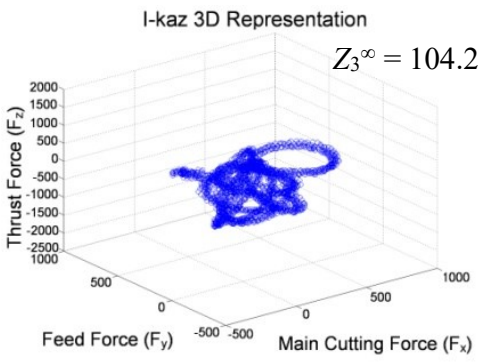

(b)

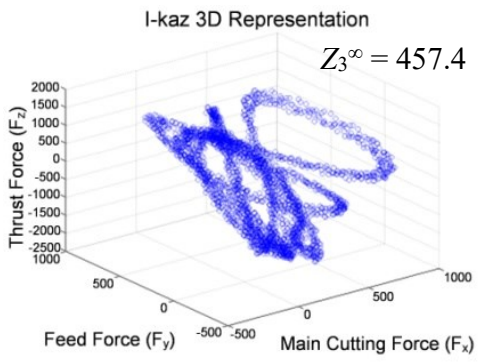

(c)

Figure 3.a) Initial phase b) Middle phase c) End phase of all experimental machining set combination. 
From Figure 2, it is shown that worn cutting tool required high cutting force compare to sharp cutting tool. From the Figure 2 also, cutting force at axial axis is dominant force compare to feed force ( $y$-axis) and main cutting force ( $x$-axis). This can be explained by Gunay et al. [20] stated that when axial depth of cut is smaller than nose radius of cutting tool, the force vector direction is close to $z$-direction and this make force at $z$-axis is dominant when compare to other forces. By referring to Figure 2, when flank wear reach $0.144 \mathrm{~mm}$, the average main cutting force ( $x$-axis) is $201 \mathrm{~N}$. After flank wear reach $=$ $0.519 \mathrm{~mm}$, the average main cutting force increases to $423 \mathrm{~N}$ or $110 \%$. The average feed force ( $y$-axis) at the initial first cutting is only $82 \mathrm{~N}$, and at the end of cutting it increases to about $186 \mathrm{~N}$ or $126 \%$. Meanwhile, the average of thrust force ( $z$-axis) at the initial first cutting is only $196 \mathrm{~N}$, and at the end of cutting, it increase to $902 \mathrm{~N}$ or $360 \%$.

By using I-kaz 3D method to analyze cutting force signal along the cutting process from sharp cutting tool until worn cutting tool, three-dimensional graphical are used to represent the scatter's degree of the data as shown in Figures 3.These plots of I-kaz3D in three-dimensional graphical are representations of amplitude scattering for main cutting force at $x$-axis, feed force at $y$-axis, and thrust force at $z$-axis signals. It can be observed that the data scattering's changes are very significant due to progression of flank wear of cutting tool. From the figures, it is clear that the shape of data scattering for same cutting condition is similar between each cutting phase except it has changes in degree of data scattering. Meanwhile, the shape of scattering data between different cutting conditions does not have similarities. It can be explained because of, the different on cutting speed will feed rate will cause different shape of data scattering. Hence each cutting condition will have unique shapes of data scattering.

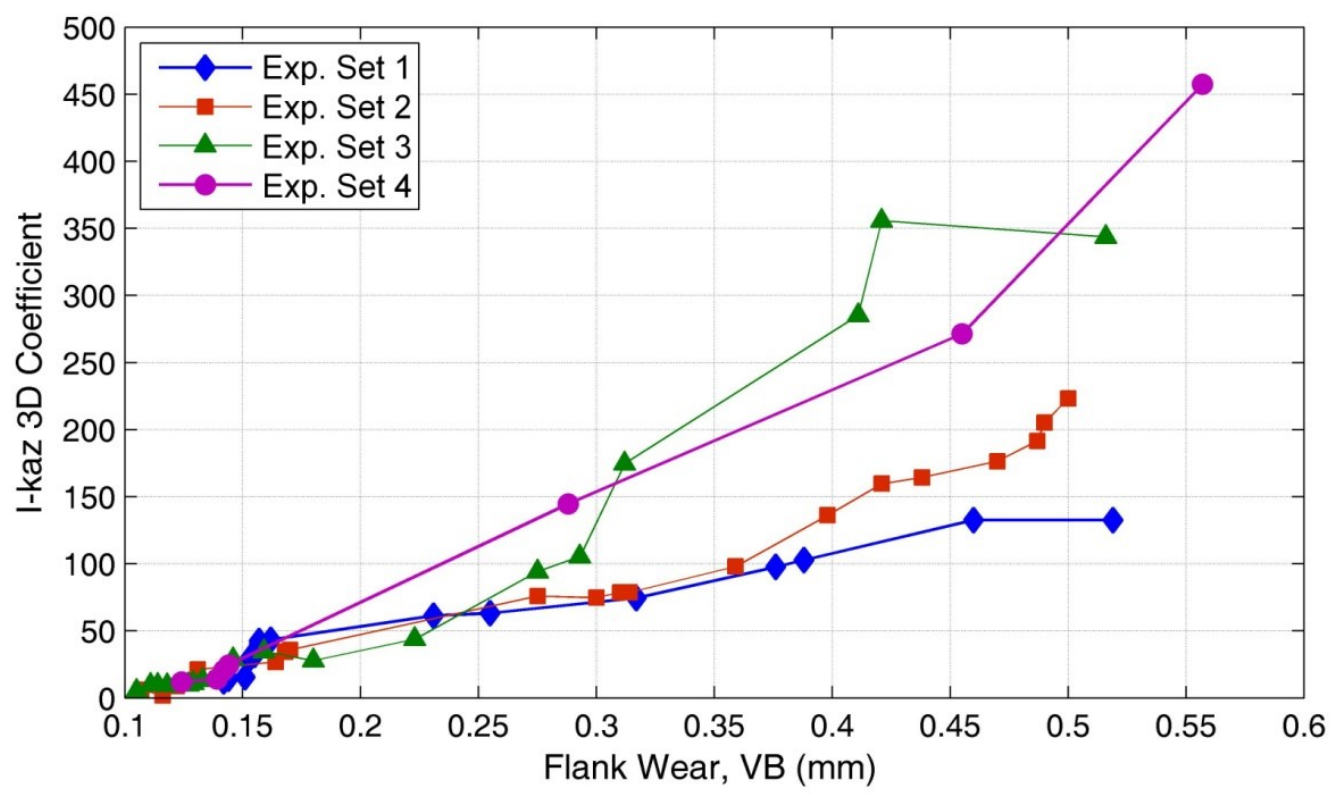

Figure 4. I-kaz 3D coefficient against flank wear.

To calculate I-kaz 3D coefficient, Eq.8 is used directly for each raw cutting force signal, and then I-kaz 3D coefficients against flank wear are plotted as shown in Figure 4. It is obviously that I-kaz 3D coefficient has a significant relation with flank wear progression during milling process. When flank wear increase, I-kaz 3D coefficient also increase. Similar to result that is reported by Rizal et al. [12] which use I-kaz 2D method to analyze cutting force in turning operation and they also observed that increasing in 
flank wear caused I-kaz 2D coefficient also increase. Different from this study, this study use I-kaz 3D to analyze cutting force in three axis while I-kaz 2D is use to analyze cutting force in two axis.

\section{CONCLUSIONS}

The application of I-kaz 3D which is a derivation of I-kaz ${ }^{\mathrm{TM}}$ method has been successfully used to analyze cutting force signal in this study. This technique is found suitable for analyzing the cutting force signal and reliable to detect flank wear change during machining process. In addition, I-kaz 3D method provides two results, both coefficient value and three-dimensional graphics which shows the data scattering of the cutting force signal. This method can be applied as early warning technique to detect flank wear progression in real industry application.

\section{ACKNOWLEDGEMENT}

The authors would like to thank the Government of Malaysia and Universiti Kebangsaan Malaysia for their financial support under UKM-GUP-2013-044.

\section{REFERENCES}

[1] Rizal M, Ghani JA, Nuawi MZ, Haron CHC. A comparative study of I-kaz based signal analysis techniques: application to detect tool wear during turning process. Jurnal Teknologi. 2014;66:99-105.

[2] Kadirgama K, Abou-El-Hossein K, Noor M, Sharma K, Mohammad B. Tool life and wear mechanism when machining Hastelloy C-22HS. Wear. 2011;270:25868.

[3] Najiha MS, Rahman MM, Yusoff AR, Kadirgama K. Investigation of flow behavior in minimum quantity lubrication nozzle for end milling processes. International Journal of Automotive and Mechanical Engineering. 2012;6:768-76.

[4] Puvanesan M, Rahman MM, Najiha MS, Kadirgama K. Experimental investigation of minimum quantity lubrication on tool wear in aluminum alloy 6061-T6 using different cutting tools. International Journal of Automotive and Mechanical Engineering. 2014;9:1538-49.

[5] Razak NH, Rahman MM, Kadirgama K. Experimental study on surface integrity in end milling of hastelloy C-2000 superalloy. International Journal of Automotive and Mechanical Engineering. 2014;9:1578-87.

[6] Najiha MS, Rahman MM, Yusoff AR. Modeling of the end milling process for aluminum alloy AA6061t6 using HSS tool. International Journal of Automotive and Mechanical Engineering. 2013;8:1140-50.

[7] Abu-Mahfouz I. Drilling wear detection and classification using vibration signals and artificial neural network. International Journal of Machine Tools and Manufacture. 2003;43:707-20.

[8] Briceno JF, El-Mounayri H, Mukhopadhyay S. Selecting an artificial neural network for efficient modeling and accurate simulation of the milling process. International Journal of Machine Tools and Manufacture. 2002;42:663-74. 
[9] Chungchoo C, Saini D. On-line tool wear estimation in CNC turning operations using fuzzy neural network model. International Journal of Machine Tools and Manufacture. 2002;42:29-40.

[10] Nuawi M, Nor M, Jamaludin N, Abdullah S, Lamin F, Nizwan C. Development of integrated kurtosis-based algorithm for z-filter technique. Journal of Applied Sciences. 2008;8:1541-7.

[11] Oskoueian A, Nuawi MZ. Internal Combustion Engine Monitoring Using Strain Gauge and Analyzing With I-Kaz. IERI Procedia. 2012;1:192-8.

[12] Rizal M, Ghani JA, Nuawi MZ, Haron CHC. The application of I-kaz TM-based method for tool wear monitoring using cutting force signal. Procedia Engineering. 2013;68:461-8.

[13] Karim Z, Nuawi M, Ghani J, Azrulhisham E, Abdullah S. Development of machining condition monitoring system using piezoelectric sensor analyzed by IKaz multilevel method. World Applied Sciences Journal. 2013;21:264-8.

[14] Ghazali M, Mansor N, Nuawi M, Ghani J. Facile wear failure monitoring of commercial bearing alloys using I-kaz method. Engineering Failure Analysis. 2013;35:545-53.

[15] Abdullah S, Ismail N, Nuawi MZ, Nopiah ZM, Baharin MN. On the need of kurtosis-based technique to evaluate the fatigue life of a coil spring. 2009 International Conference on Signal Processing Systems. 2009. p. 989-93.

[16] Nuawi M, Lamin F, Abdullah S, Nor M. J. M., Arifin A. Clustering of machining signal for verifying machining parameter. Proceedings of the 1st WSEAS international conference on Sensors and signals: World Scientific and Engineering Academy and Society. 2008. p. 54-9.

[17] Aziz SAA, Nuawi MZ, Nor M, Jailani M, Daruis DDI, Bahari AR. Correlation between whole body vibratio exposure and I-KazTM 3D coefficient for Malaysian army 3-tonne truck drivers. Applied Mechanics and Materials: Trans Tech Publ; 2014. p. 156-60.

[18] Yunoh M, Abdullah S, Saad MHM, Nopiah ZM, Nuawi MZ. Fatigue feature extraction analysis based on a K-means clustering approach. Journal of Mechanical Engineering and Sciences. 2015;8:1275-82.

[19] Sharman A, Dewes RC, Aspinwall DK. Tool life when high speed ball nose end milling Inconel $718^{\mathrm{TM}}$. Journal of Materials Processing Technology. 2001;118:2935.

[20] Gunay M, Kacal A, Turgut Y. Optimization of machining parameters in milling of Ti-6Al-4V alloy using Taguchi method, eJ. New World Science Academy Engineering Sciences. 2011;6:428-40. 